\title{
Ser rabino, como profesión y estilo de vida. Claves para (re)pensarlo en el mundo del trabajo reconfigurado ${ }^{I}$
}

\author{
Be rabbi, as a profession and lifestyle. Keys to (re)think it in the labor world \\ reconfigured
}

\section{Resumen}

En esta propuesta se busca dar cuenta de la trayectoria de dos rabinos judíos ortodoxos sefaradíes, con el tinte particular de ser abuelo y nieto (por cuestiones de anonimato, hemos modificado sus nombres). Para ello se ha entrevistado al nieto, Isaías, quien actualmente es rabino de una escuela (en los tres niveles: jardín, primaria y secundaria), él fue quien nos dio acceso a la historia de vida de su abuelo, Ismael. La cual se encuentra compilada en un libro (que nos fue obsequiado), que la comunidad armó al cumplirse el año de fallecimiento de Ismael. La intención es poder dar cuenta, con la historia de vida de Ismael y la entrevista a Isaías, de las diversas formas en que los judíos expresan y vivencian su creer, así como las prácticas en relación a pertenecer a las tradiciones, en este caso será la especificidad que existe, dentro de los judíos ortodoxos sefaradíes de origen (y descendencia) siria, del especialista religioso. Siendo las experiencias de los especialistas religiosos judíos, es decir, quienes eligen como modo de vida dedicarse a la práctica, enseñanza, difusión y ejercicio de la religión. La propuesta implica poner en palabras distintas cotidianeidades de estos dos especialistas, su relación con los marcos comunitarios e institucionales de los que forman parte.

Palabras clave: Especialista religioso, Ser judío, Modo de vida, Representaciones.

\begin{abstract}
This proposal seeks to account for the trajectory of two Sephardic Orthodox Jewish rabbis, with the particularity of being grandfather and grandson (for reasons of anonymity, we have modified their names). The grandson Isaiah, who is currently a rabbi of a school (in the three levels: garden, primary and secondary), has been interviewed, he was the one who gave us access to the life story of his grandfather, Ismael. The Ismael life's story is compiled in a book (that was given to us). His community, compiled after the year of Ismael's death. Our intention is to be able, with the life story of Ishmael and the interview with Isaiah, to tell the different ways that the Jews express and experience their belief, as well as the practices in relation to belonging to the traditions. In this dossier it will be the specificity that exists, within the Orthodox Sephardic Jews of Syrian origin (and their descent), of what it means to be a religious specialist. The Jewish's religious specialist experiences are those who choose as a way of life to dedicate themselves to the practice, teaching, diffusion and the religion exercise. The proposal involves putting in words the different daily lives of these two specialists, their relationship with the community and institutional frameworks of which they are part.
\end{abstract}

\footnotetext{
${ }_{1}$ El presente artículo forma parte de la tesis de maestría en investigación en ciencias sociales. Beca maestria UBACYT en curso.

2 Magali Katz es licenciada en sociología por la Universidad de Buenos Aires. Docente de metodología de investigación social en la Facultad de Ciencias Sociales de la UBA. E-mail: magalikatzok@gmail.com. Cidade: Buenos Aires.
} 
Keywords: Religious specialist, Being Jewish, Way of life, Representations.

\section{Introducción}

El objetivo de este trabajo es poder dar cuenta de lo que significa ser rabino, como profesión y estilo de vida en la Argentina. Dado que existen fundamentalmente dos corrientes al interior del judaísmo, nos referimos a la corrientes ashkenazi (proveniente de la zona de Europa central, fundamentalmente Rusia) y la sefaradí (remite a los y las judíos/as que se establecieron en sociedades de cultura árabe o de religión musulmana, norte de África, Península Arábiga, Turquía, y que datan de los tiempos en que la península ibérica estaba en poder de los musulmanes siglo VIII al XV), es que en este trabajo optamos por focalizar en la trayectoria de dos especialistas religiosos judíos, sefaradies, de procedencia siria. Para lo cual, consideraremos dos técnicas cualitativas, la entrevista y la historia de vida. A continuación haremos algunas aclaraciones sobre que entenderemos en este artículo por trayectoria, especialistas religiosos, sefaradies, de procedencia siria, entrevista e historia de vida.

Cuando hablamos de trayectoria, coincidimos con LAHIRE, quien en una entrevista dada en el $2008^{3}$, sostenía que cuando hablamos de trayectorias sociales, laborales y educativas, nos estamos refiriendo al capital social, el cual deviene en un activo de gran importancia. Bourdieu, por su parte define capital social como el conjunto de relaciones actuales o potenciales relacionadas con la posesión de una red durable de relaciones más o menos institucionalizadas entre-conocimiento y entre-reconocimiento. Es aquella totalidad de recursos basados en la pertenencia a un grupo. Sean recursos potenciales o actuales, asociados a una red de relaciones más o menos institucionalizadas, esto es, en sus propias palabras:

En la práctica, las relaciones de capital social sólo pueden existir sobre la base de relaciones de intercambio materiales y/o simbólicas, y contribuyendo además a su mantenimiento. Pueden asimismo ser institucionalizadas y garantizadas socialmente, ya sea mediante la

\footnotetext{
3 Véase GESSAGHI V. Y SENDÓN M. A. (2008) Socializaciones y disposiciones heterogéneas: sus vínculos con la escolarización en Revista propuesta educativa Numero 30. Noviembre. La tensión entre lo $\begin{array}{lllllll}\text { universal } & \mathrm{y} & \text { lo } & \text { particular } & \text { en } & \text { la } & \text { forma }\end{array}$ http://www.propuestaeducativa.flacso.org.ar/archivos/entrevistas/30.pdf [16/09/2018].
} 
adopción de un nombre común, que indique la pertenencia a una familia, una clase, un clan, o incluso a un colegio, un partido (BOURDIEU, 2001, p.149).

Respecto a trayectoria la define como

\begin{abstract}
la serie de posiciones sucesivamente ocupadas por un mismo agente o grupo de agentes en espacios sucesivos. Es respecto a los estados correspondientes de la estructura del campo como se determinan en cada momento el sentido y el valor social de los acontecimientos biográficos, entendido como inversiones a largo plazo y desplazamientos en este espacio [...] o en los estados sucesivos de la estructura de la distribución de las diferentes especies de capital que están en juego en el campo, tanto económico, como simbólico como capital especifico de consagración" (BOURDIEU, 1995, p. 384).
\end{abstract}

En cuanto a especialista religioso, a aquel lider, figura que dentro de su comunidad es "consagrando solemne y públicamente, haciendo discontinuo lo continuo, y que instituye una diferencia como legitima y se construye asi un orden basado en distinciones destinadas a naturalizarse" (MARTÍNEZ, 2009).

Nos interesa analizar la proyección de esos especialistas en un contexto donde tanto los creyentes como las creencias se modifican y recomponen al interior de transformaciones económicas y sociales (MALLIMACI y BÉLIVEAU, 2007; MALLIMACI, ESQUIVEL y BÉLIVEAU, 2009; MALLIMACI, 2013). Esto porque consideramos que el espacio religioso se ha caracterizado a lo largo de la historia argentina y latinoamericana, por ser particularmente fructífero en la producción de líderes que han atravesado las fronteras de lo religioso para incursionar en otros campos de actividad e inclusive instalarse en ellos como referentes y productores de sentidos.

El judío ortodoxo es aquel que pretende mantener la práctica y observancia del judaísmo de manera estricta y ligada a las leyes de dios expresadas en la Tora (Palabra en hebreo que remite a instrucción, enseñanza. Es el texto que contiene la ley y el patrimonio identitario judío), y reglamentadas en la Halajá (Palabra en hebreo, es el conjunto de reglas judías derivadas de la torá escrita y oral, incluyendo las 613 mitzvot (preceptos). La práctica cotidiana de este tipo de judaísmo implica una gran 
cantidad de observaciones y actos litúrgicos que a su vez requieren de una determinada estructura comunitaria.

Hacemos estas aclaraciones a partir de que, especificamente en Argentina, existen otro tipo de especialistas religiosos ortodoxos judíos, nos referimos a Jabad Lubavitch ${ }^{4}$, quienes en relación con, y desde su comunidad, cuentan con características disimiles a las aquí desarrolladas, sin embargo, en el transcurso del trabajo haremos algunas menciones al respecto. Fundamentalmente en lo que refiere a los orígenes, costumbres, así como las vías de comunicación con las y los miembros de la comunidad.

Respecto a los especialistas religiosos de procedencia siria debemos en principio aclarar que, si bien la mayor parte de los árabes-hablantes que llegaron a la Argentina provenían de Siria y el Líbano, se los llamó "turcos" (JOZAMI, 1993), desde 1888, pues su documentación era del Imperio Otomano, hecho que se repite en el censo de $1895^{5}$.

Sin embargo, más allá de cómo eran llamados, podemos caracterizarlos a partir de sus labores y saberes. De los sirios pioneros en emigrar a Argentina, en su mayoría eran agricultores o comerciantes, en algunos casos aislados disponian de un oficio o profesión liberal. Dada la extremada juventud característica de los migrantes que se reclutaban principalmente entre los 15 y 25 años, hombres, solteros, o al menos viajando solos, es que pudieron orientarse hacia otros destinos ocupacionales entre los cuales predominó el comercio (TASSO, 1990), este fue un rasgo común a muchos inmigrantes de distinto origen, en parte motivado por las reducidas posibilidades que nuestro país otorgó

\footnotetext{
${ }^{4}$ Es una organización judía jasidica, cuya sede central se encuentra en Brooklyn, New Yortk, Estados Unidos. Fue fundada por el rabino SCHNEUR ZALMAN (1745-1812). En la actualidad esta corriente se adhiere a las enseñanzas del rabino Menachem Mendel Schneerson. Jabad es el acróstico en hebreo de jojma (su traducción es inspiración), binà (entendimiento) y daat (conciencia). Respecto a Lubavitch es el nombre de una población en Rusia (Lyubavichi, que significa "ciudad del amor"). Por tanto, Jabad es una corriente con especialistas religiosos judíos ortodoxos ashkenazi, más adelante en el trabajo se verá en profundidad la diferencia entre ashkenazi y sefaradí. Para más información sobre Jabad, véase www.jabad.org.ar [13/09/2018].

5 Para más información ver http://www.indec.gob.ar/nivel3_default.asp?id_tema_1=2\&id_tema_2=41 [13/09/2018].
} 
efectivamente para acceder a la producción agropecuaria a los inmigrantes (DEVOTO, 1995).

Así es que en las listas de oficios declarados al llegar al país figuraban: agricultores, aunque predominaban comerciantes, jornaleros y personas sin oficio. La escasez de otras alternativas ocupacionales condujo a los migrantes sirios hacia una actividad típicamente informal, que no exigía capital, y que se abrió paso rápidamente entre los intersticios de una red comercial todavía incipiente en el país, estamos hablando de la venta ambulante. Es indudable que esta actividad permitió la socialización básica de los inmigrantes: aprendizaje del idioma, dominio de la topografia urbana y rural, así como el conocimiento de los códigos sociales (TASSO, 1990; KLICH, 2004; AKMIR, 2009 y 2011). Pero no solo eso, el objetivo era reunir el capital suficiente como para establecer un comercio (de acuerdo con la ocupación que por generaciones había mantenido a su familias en la tierra natal), o de retornar a sus lugares de origen (BIANCHI, 2004), sin embargo entre los sirios, el retorno es lo que menos ocurrió. Así es que, han ido distribuyéndose de acuerdo a patrones similares al resto de los colectivos migrantes, lo cual remitía a permanecer en CABA, y radicarse en mayor número en la región pampeana (KLICH, 2004). Hubo entonces, como hay aún ahora, quienes se dirigieron a Córdoba, Santiago del Estero, Tucumán, Catamarca, Salta y La Rioja, donde hubo notables posibilidades ocupacionales con una incipiente red comercial (TASSO, 1990; AKMIR, 2009 y 2011).

Como recuerda Nissim Teubal allá por $1906^{6}$, junto a su hermano Ezra comenzaron como "jameleros" (jamle en árabe significa "paquete que se lleva al hombro"), es decir como vendedores ambulantes, su historia es significativa pues representa las posibilidades de ascenso social que se abrieron paso a los inmigrantes en la Argentina. En el transcurso del artículo, a partir de la historia de vida de Ismael ahondaremos sobre esto.

6 Citado en Bianchi, 2004. 
Mallimaci y Giménez Béliveau, (2006), indican que la técnica de la entrevista refiere a un relato pronunciado en primera persona, ya que lo que se intenta rescatar son las experiencias de ese individuo. Casi nunca se pretende que sea exhaustivo, sino que se centra en algún momento o aspecto de la vida. También la ilusión de la totalidad está desterrada, porque se considera que todo sujeto posee un mecanismo selectivo que desde el presente lo lleva a recordar u olvidar determinados hechos, y dicho proceso debe ser respetado por el investigador. Es necesario aclarar que en tanto el individuo se posiciona en primera persona y habla de sus experiencias, se lo considera el personaje del relato. No importa si dice absolutamente todo, ni si respeta el orden cronológico, sino los hechos que son iluminados por la selección del recuerdo y la lógica de conexión que se evidencia en el relato. Hay que tener presente que todo relato biográfico es focalizado, parcial, y su primer recorte está dado por el investigador mismo con base en su interés de conocimiento. Tampoco debe importar si las cosas ocurrieron tal cual lo contado, ni si es absolutamente 'verdad'. Esto se basa en que si no sucedió así, por lo menos desde el presente se lo concibe de esa manera y por lo tanto se actuará en consecuencia.

En lo que a Historia de vida ${ }^{7}$ refiere, Mallimaci y Giménez Béliveau, (2006), nos indican que remite al estudio, investigación y/o análisis sobre una persona determinada que, incluye su propio relato, pero que es complementado por el investigador con otras clases de documentos 0 narraciones. Se basa en recorridos amplios en la vida de un sujeto; lo que interesa es una suerte de totalidad, donde el orden cronológico tiende a ser respetado.

\footnotetext{
7 Véase también DUVIGNAUD (1979) Sociología del Conocimiento, F.C.E., México; MAGRASSI, guillermo E. Y ROCA, manuel M., (1980) La "Historia de Vida", Centro Editor de América Latina, Buenos Aires; FERRAROTTI, franco (1981), Storia e storie di vita, Laterza, Roma-Bari; POIRIER, jean y otros, (1983) Les récits de vie, Presses Universitaires de France, París; PLUMMER, ken, (1989) Los documentos personales, Siglo xxi, Madrid, 1989; CÓRDOVA, víctor, (1990) Historias de Vida, Fondo Editorial Tropykos, Caracas; DUVIGNAUD jean (1991) La Historia y lo cotidiano, Península, Barcelona; PUJADAS MUÑOZ, juan josé, (1992) El método biográfico: El uso de las historias de vida en ciencias sociales, Centro de Investigaciones sociológicas, Madrid; DE MIGUEL, jesús M., (1996) Auto/biografias, Centro de Investigaciones Sociológicas, Madrid.
} 
Se basa en un amplio recorrido en la vida de una persona donde los hechos cronológicos son el hilo conductor. Se toma al individuo en calidad de partícipe $\mathrm{u}$ observador de un hecho significativo en un momento $\mathrm{y}$ acontecimiento significativo. Interesa más el acontecimiento que la historia de vida ${ }^{8}$. La historia oral presenta también sus diferencias dado que ésta puede ser considerada como el análisis de fuentes orales para analizar los hechos históricos con otras voces que son otros documentos, especialmente de sectores no hegemónicos. Hay sensibilidades comunes aunque las diferencias existen a pesar que a veces parezcan minimas. Conocerlas permite una mejor comprensión. Éstas han sido algunas de las características que tanto Bertaux $(1988,1993)$ como Ferrarotti $(1988,1991)$ -ambos con una amplia trayectoria en la aplicación de historias de vida en sus investigaciones- defienden, como parte de reivindicar lo biográfico en tanto enfoque teórico -metodológico y no simplemente como herramienta o técnica. El primero insiste en historias de familias y en sumar otras fuentes, el segundo sólo se interesa en el relato de vida de una persona pues ella sintetiza lo social, lo estructural, las múltiples mediaciones.

Meccia (2013), por su parte, nos ayuda a "prestar atención a los recursos con los cuales los actores arman sus discursos", en nuestro caso serán aquellos que remiten a dos especialistas religiosos lo cual nos permitirá rastrear elementos imaginarios y simbólicos atinentes a qué significa ser especialista religioso judío, ortodoxo, sefaradí, de ascendencia siria en la Ciudad Autónoma de Buenos Aires.

Asimismo es menester recordar la aclaración de Kornblit (2004), la de estar atentos a la dimensión discursiva de los fenómenos sociales y al fenómeno mismo del discurso social. En este trabajo se considerará fundamental el discurso de dos especialistas religiosos, un abuelo, y un nieto, buscando la continuidad, ruptura, similitud y/o diferencias que

\footnotetext{
8 Por ejemplo SEOANE-MULEIRO, en "El dictador. La historia secreta y pública de Jorge Rafael Videla" (editorial Sudamericana, Buenos Aires, 2001), busca a partir del testimonio del dictador Videla, junto con otras entrevistas, dar cuenta de lo que fue la dictadura cívico-militar en la Argentina entre 1976 y 1983.
} 
pudieran existir entre las trayectorias, de ese saber hacer, en Argentina, uno en los primeros años de la década de 1950, el otro en la actualidad.

Razón por la cual consideramos pertinente estructurar el trabajo en cuatro partes. La primera tiene que ver con dar cuenta de un marco sociocontextual para especificar cómo fueron llegando los judíos a la Argentina. En segundo lugar indicar las diferentes corrientes que existen al interior del judaísmo, dentro de estos contingentes migratorios. Profundizaremos a continuación sobre los especialistas religiosos, tomando como estudio de caso al judio ortodoxo, a partir de una entrevista y una historia de vida, pudiendo dar cuenta cómo es que estos especialistas toman contacto con la religión, considerando el contexto y particularidades de ambos, su formación, los aportes que han hecho a la comunidad a la que pertenecen, así como su legado. Como dijéramos, a partir de continuidades, rupturas, diferencias y similitudes entre especialistas, en relación a otros, por ejemplo Jabad Lubavitch ${ }^{9}$.

Cerraremos el articulo con algunas reflexiones echando luz sobre la importancia de la transmisión de un modo de vida, englobando una profesión, una tradición y todo lo que ello conlleva siendo sirio, y descendiente de sirios, judío ortodoxo sefaradí.

\section{De cómo fueron llegando}

En este apartado daremos un marco socio-contextual para poder especificar cómo fueron llegando los judios a la Argentina. Desde hace más de dos mil años, los y las judíos/as constituyen una minoría religiosa y étnico-cultural dispersa por todo el mundo. Como minoría, los y las judíos/as debieron integrarse mayoritariamente en ámbitos urbanos o semiurbanos, ya que con frecuencia no tenían acceso a la tierra. Así, la mayoría de ellos/as se dedicaba a profesiones o labores propias de las ciudades: comercio, artesanado, o bien alguna intermediación entre campo y ciudad, entre otras actividades. Frente a las prohibiciones para adquirir bienes

9 Ídem nota 2 
inmuebles y ante el peligro de expulsiones en la Europa medieval y moderna, los y las judíos/as solian invertir en bienes que pudieran llevarse con ellos. Podian trasladar pequeños objetos vendibles en cualquier mercado, o el llamado capital cultural, es decir, la educación y el estudio.

Con el desarrollo de los centros urbanos, sobre todo a partir del siglo $\mathrm{XV}$, pudieron, cuando las leyes se lo permitian, acceder a las profesiones liberales en las universidades. A grandes rasgos, podemos diferenciar dos principales grupos de judíos/as. En primer lugar, los que se establecieron en sociedades de cultura árabe o de religión musulmana (norte de África, Península Arábiga, Turquía). En segundo lugar, los y las que se instalaron en sociedades en las cuales el cristianismo era la religión mayoritaria (Europa). Los primeros son conocidos como judíos sefaradies, de Sefarad, que en hebreo significa España, y que datan de los tiempos en que la península ibérica estaba en poder de los musulmanes (siglo VIII al XV).

Las grandes comunidades judías de Europa Oriental surgieron hacia el siglo XV como consecuencia de persecuciones o expulsiones sufridas en Europa Occidental. Entre los y las judíos/as el territorio centroeuropeo era conocido como Ashkenaz, por lo cual esas comunidades son denominadas askenazies. Mientras que los judíos sefaradies hablaban el árabe (turco o farsi en el caso de Turquía e Irán respectivamente) o, en determinadas regiones, el ladino (una lengua que solo manejaban ellos), los judíos askenazies desarrollaron su lengua propia, el idish. Escrito con caracteres hebreos, el idish se formó con aportes de lenguas europeas como el alemán, combinado con hebraísmos y palabras eslavas.

Recién a partir de finales del siglo XVIII y a lo largo de todo el siglo XIX, los y las judíos/as de Europa Occidental fueron incorporados/as, considerados/as como ciudadanos/as de los países en los cuales vivian, a veces desde hacía siglos, adquiriendo cada vez más derechos. Sin embargo, en el Imperio Ruso, donde residía la mayor cantidad de judíos/as, esos derechos no llegaron a otorgarse nunca. Razón por la cual gran cantidad de 
ellos/as migraran a diferentes lugares del mundo, uno de ellos, América, esta es la línea de Jabad Lubavitch.

Habiendo indicado las dos grandes líneas de judaísmo existente, quisiéramos plantear cómo se fueron sucediendo las migraciones de judíos/as a la Argentina. Podríamos indicar cuatro grandes momentos de flujo migratorio, el primero remite a aquellos años anteriores a 1889. En ese entonces quienes arribaron provenían principalmente de Francia, Alemania y Austria. Llegaban como representantes de casas europeas dedicadas a la exportación e importación. Casi todos eran técnicos o profesionales liberales. Se educaron en un universo de emancipación civil con un alto índice de identificación con la burguesía europea occidental. Así es que ya en 1889, dos años antes de que el Barón de Hirsch ${ }^{10}$ formulará y concretara su ideal y proyecto de fundar grandes colonias judías en la Argentina con los y las judíos/as perseguidos en Europa, el proceso de inmigración agrario de éstos se inició con el grupo de Kamenetz ${ }^{11}$ que dieron luego lugar a la fundación de Moisés Ville (Santa Fe), signo emblemático del proceso de colonización (HERSZKOWICH, 2013). Por estos años, también arribaron inmigrantes sefaradíes tanto de habla árabe (Siria y Líbano) como de habla ladina (Turquía, Grecia y los Balcanes) como figura en los registros de lo que hoy conocemos como la Dirección de Migraciones.

Según el Censo de la Municipalidad de Buenos Aires, realizado en 1887 , en la ciudad ya había 366 judíos. Por esa misma época anclaron también judíos de origen sefaradí, que escapaban de la guerra hispanomarroquí (HERSZKOWICH, 2013).

Un segundo período remite a los años entre 1890 y 1914, coincide con lo que se denominó migraciones de masas (DEVOTO, 2003; BIANCHI,

\footnotetext{
10 Maurice de Hirsch nació en Munich, en el seno de un hogar judío de habla alemana, en 1831.Tras la muerte de su hijo se dedicó a aliviar el sufrimiento de los judíos de Rusia y de distintas partes del mundo. En 1891 Fundó la Jewish Colonization Association (JCA o Fundación Barón Hirsch) con el objetivo de demostrar que los judíos podían ser excelentes agricultores. Tras la colonización judía en Argentina iniciada en 1889, en 1891 ya con la J.C.A. en funciones, se multiplican las colonias en nuestro país.

11 Kamenetz es la principal ciudad de Podolia, una región de la Europa Oriental que se encuentra actualmente en la zona centro occidental y sudoccidental de Ucrania y que, en líneas generales, corresponde a los actuales óblast de Jmelnitski, Ternopil y Vínnytsia.
} 
2004), y es cuando llegaron principalmente judíos polacos, ucranianos y, sobre todo, rusos que escapaban de los pogroms ${ }^{12}$.

Un tercer momento remite a la presencia migratoria en las ciudades. Tras la Primera Guerra Mundial se reanuda intensamente la inmigración judía a la Argentina principalmente de Polonia y Turquía. Si bien continúan llegando a las colonias del Barón Hirsch, esta migración se destaca por ser principalmente de obreros, artesanos y trabajadores manuales que instalan los primeros talleres manufactureros en Buenos Aires. Para esta época, la proporción de judios/as residentes en el campo se había modificado: sólo el $22 \%$ de los y las judios/as argentinos/as vivía en las colonias agrícolas. Para 1935, la cifra había bajado al 11\% (GERMANI, 1963; HERSZKOWICH, 2013).

La cuarta gran ola migratoria coincide con judíos refugiados de Alemania, Austria, Hungría, Polonia y Rumania, que escapaban del régimen nazi. El comienzo de la deportación de judíos a campos de concentración en 1938 y, un año después, el inicio de la Segunda Guerra Mundial dificultó ya la llegada en masa.

Habiendo presentado el panorama general de la llegada de los judíos a la Argentina y de los diferentes lugares de asentamiento, destacamos su focalización en las grandes urbes. Así nos interiorizamos en el área de investigaciones sobre lo urbano que no son nuevas en la sociología, puesto que, ya desde los inicios, los "padres fundadores" de una u otra manera las han tenido en cuenta. La idea de la extinción de la "sociedad rural" y la llegada de una nueva era industrial centrada en la ciudad es parte central del "mito fundador" de la sociología. Así, en ciertos discursos, teorías y paradigmas sociales ciudad se asociaba a ciencia, a civilización, movimiento obrero, progreso, cosmopolitismo, desarrollo, racionalidad, lucha social, modernidad (FORNI, MALLIMACI, CÁRDENAS, 2008, P. 17). Asimismo ya en

12 Palabra rusa que significa devastación. Su origen se remonta a 1881 cuando luego del asesinato del zar Alejandro II en San Petersburgo se produce una oleada de violencia prolongada que incluye la destrucción de objetos sagrados, incendios, e incluso violaciones. Son persecuciones, que en muchos casos culminan en matanzas, donde la opción es el enfrentamiento, o la migración forzada de una comunidad completa. Otros ejemplos mencionables son los sucedidos durante la Revolución Rusa de 1917, durante la Segunda Guerra Mundial, o el Enero Negro en Bakú durante 1990. 
2008 Forni advertía, "Vivimos un crecimiento continuo de población en ciudades y suburbios, concentración de riqueza junto a una heterogeneidad de la pobreza, acumulación sin freno junto a crecimiento del desempleo y nuevas marginalidades; crisis de representaciones sociales, políticas y simbólicas" (FORNI ET AL., 2008, p. 20). Y en la misma línea agrega:

la ciudad no vive solamente de las creencias de los "establecidos" sino que continuamente recibe nuevos aportes de aquellos que viven alli provenientes de lugares diversos y con la posibilidad - o no - de establecerse definitivamente en ella. Las ciudades son hoy un espacio donde la diversidad y la pluralidad religiosa son no solamente toleradas sino que forman parte de la comprensión que se tiene de las creencias en el tercer milenio (FORNI ET AL., 2008, p. 21).

Habiendo dado un marco socio-histórico de cómo fueron llegando los judíos a la Argentina, daremos paso al segundo apartado, buscando dar cuenta de las diferentes corrientes que existen al interior del judaísmo, dentro claro está, de estos contingentes migratorios.

\section{Corrientes al interior del judaísmo en la Argentina}

Dentro de cada una de las dos líneas de judaísmo, recordemos, la ashkenazi, y la sefaradí, en función del origen migratorio que hemos descrito brevemente, es necesario observar la existencia de diversas corrientes en función de sus prácticas y concepciones religiosas. Nos referimos a la Ortodoxia, conservadurismo y reformismo. Estas son las tres corrientes más difundidas y establecidas en la Argentina. La ortodoxia pretende mantener la práctica y observancia del judaísmo de manera estricta y ligada a las leyes de dios expresadas en la Torá ${ }^{13} y$ reglamentadas en la Halajá ${ }^{14}$. La práctica cotidiana del judaísmo implica así una gran cantidad de observaciones y actos litúrgicos que a su vez requieren de una determinada estructura comunitaria. La corriente conocida como conservadora está vinculada principalmente al Movimiento Masortí15 que plantea mantener los valores y

13 Palabra en hebreo que remite a instrucción, enseñanza. Es el texto que contiene la ley y el patrimonio identitario judio.

14 Palabra en hebreo, es el conjunto de reglas judías derivadas de la torá escrita y oral, incluyendo las 613 mitzvot (preceptos).

$15 \mathrm{El}$ movimiento Masortí o conservador surge en Alemania a mediados del siglo XIX como una reacción al judaísmo reformista, posicionándose como una síntesis entre este último y el judaísmo 
las prácticas principales del judaísmo teniendo en cuenta los contextos de vida contemporáneos. De esta manera se intenta adaptar la práctica del judaísmo en relación a la modernidad sin dejar de tener como referencia a las leyes Halájicas ${ }^{16}$ pero siendo flexibles en cuanto a su estricta aplicación. Por último, el judaísmo reformista ${ }^{17 i n f l u e n c i a d o ~ d e s d e ~ s u s ~ o r i ́ g e n e s ~ p o r ~ l o s ~}$ movimientos iluministas de occidente, propone un judaísmo abierto a los conocimientos del mundo secular, defendiendo la autonomía individual en lo relativo a la interpretación de los preceptos religiosos.

Existen trabajos e investigaciones que enmarcan su análisis sobre liderazgos judíos, sobre la comprensión del judaísmo como amalgama entre religión, etnicidad y cultura. Rosenberg y Rubinstein-Novick (1961) analizan la emergencia y consolidación de la comunidad judía en el periodo 18601961, marcando en los inicios la preeminencia de un judaísmo de corte secular que desdibujó la autoridad rabínica. La corriente migratoria anterior a la segunda guerra mundial supuso la radicación de inmigrantes vinculados a la dimensión religiosa del judaísmo, alterando la fisonomía de la comunidad judía de la Argentina. En esta época el Rabinato se integra a la comunidad y surge la figura del rabino joven nacido en el país.

Los estudios sobre el Movimiento Conservador se centran en la llegada al país del rabino Marshall Meyer, quien plasmó una propuesta religiosa que dialogaba con las necesidades de una juventud poco propensa al estilo tradicionalista $\mathrm{u}$ ortodoxo. El movimiento conservador habría restituido a la sinagoga en el centro del espacio de socialización de los judíos, de ahí que Fainstein (2006) encuentre en su desarrollo un antecedente a la posterior revitalización de la ortodoxia. Los años ochenta y

ortodoxo. Junto a estos dos, el judaísmo conservador es una de las tres grandes corrientes religiosas del judaísmo. El judaísmo conservador se institucionalizó en los EE. UU. alrededor del 1900. El conservadurismo postula la devoción a la tradición y ley judía (masoret y halajá), con un acercamiento abierto y positivo al mundo moderno, la democracia y el sionismo. Los principios del Judaísmo Conservador incluye: La "dedicación a la Halajá como guía para la vida; Una aceptación tanto de los métodos tradicionales-rabínicos como de los académicos y críticos en lo que al estudio de los textos religiosos del judaísmo se refiere.

16 ver nota 6.

17 El rabino Abraham Geiger (1810 - 1874) es considerado el "padre" del reformismo. 
noventa serán testigos de la organización institucional del movimiento de retorno a las fuentes, lo que colocará a la figura rabínica en el centro de la producción de lo judío y la expansión del movimiento por fuera de la ortodoxia.

El proceso de revitalización de la ortodoxia ha incentivado un conjunto de trabajos sobre los liderazgos religiosos, tanto rabínicos como laicos que, editados por las mismas instituciones religiosas, han tendido a la apología de estas figuras (BENCHIMOL, 2007; BARGMAN, 1995). Finalmente, se ha observado cómo la perspectiva de género ha influenciado en los estudios sobre liderazgo religioso, como en el caso de los estudios sobre el ejercicio del rabinato en mujeres (CABABIÉ- SCHINDLER, 2011).

Ahondaremos a continuación sobre los especialistas religiosos judios ortodoxos de origen sefaradí, a partir de la experiencia de dos estudios de caso, uno contextualizado en la década de 1950, y otro en la actualidad, contando con la particularidad de ser abuelo y nieto. Buscaremos dar cuenta cómo es que estos especialistas toman contacto con la religión, considerando contexto y particularidades de ambos, su formación, los aportes que han hecho a la comunidad a la que pertenecen, así como su legado. Como dijéramos, a partir de continuidades, rupturas, diferencias y similitudes entre especialistas. Cuando fuere necesario haremos referencias a los especialistas religiosos ashkenazies, que aquí serán considerados como los de Jabad Lubavitch.

\section{Especialistas religiosos judíos ortodoxos sefaradíes. Estudio de caso}

Comenzaremos este apartado dando cuenta en principio de la historia de vida de Ismael, su nacimiento, su formación, como llega a la Argentina, cuales son los aportes que hizo a la comunidad de la cual supo formar parte, como se vinculaba con los miembros de la comunidad, cuál fue su legado. Para luego, dar paso a la entrevista que se le realizo a Isaías, buscando en principio continuidades, rupturas, diferencias y similitudes. 
Ismael nace en el año 1912 en Alepo, Siria. Su padre es reclutado por el ejército para participar en la Gran Guerra18, mientras que su madre comenzó a buscar maneras alternativas de llevar alimento a la casa, desde vender artículos, ropa o bien hacer arreglos en vestimenta. Su hermana vendia dulces, y su hermano mayor se hizo changador. Terminada la Primera Guerra Mundial, Francia obtuvo el mandato sobre Siria, a través del acuerdo Skyes-Picot ${ }^{19}$ y la ocupó militarmente, al mismo tiempo este hecho remite al momento de auge de emigración, dentro del territorio, como hacia otros destinos, como fue América. En este contexto, la madre de Ismael decide que lo mejor para el niño será mandarle a Tédef, un pueblo a una hora en auto (hoy día) de Alepo. Allí se quedo Ismael hasta que su padre regreso de la guerra.

Los años de escolaridad y formación de Ismael, recordemos; guerra, hambre, miseria, enfermedad y muerte, consideramos, no son datos menores, puesto que hacen de su formación, una situación privilegiada, casi única, en relación al resto de los y las sirios/as de ese momento, al tiempo que le permite forjar principios y valores, destacables. Intentemos por unos segundos considerar lo que podría significar ser judío en Siria, una vez finalizada la primera guerra mundial, bajo ocupación militar de Francia. Por ello es que remarcamos sus principios y valores, puesto que, como veremos en el transcurso de este relato, Ismael logro mantener la lucha por el cumplimiento de las mitzvot20 a un nivel, estricto e insistente.

\footnotetext{
18 Uno de los nombres con lo que se conoce a la primer guerra mundial, enfrentando a la triple Alianza, formada por el Imperio Alemán, Austria e Hungria, por un lado y, a la triple Entente, Reino Unido, Francia y el Imperio ruso (luego se sumaron Italia, Japón y Estados Unidos) por el otro. La guerra duro cuatro años, entre 1914 y 1918.

19 conocido también como el Acuerdo de Asia Menor, fue un acuerdo secreto entre Reino Unido, Irlanda y Francia para definir las esferas de influencia y control sobre el territorio de Asia, en virtud de que sucedería si la triple entente (remite al Imperio alemán, Austria e Hungría) obtuviera la victoria respecto el Imperio Otomano durante la Primer Guerra Mundial. Las negociaciones se desarrollaron durante el transcurso de la guerra, más específicamente entre noviembre de 1915 y marzo de 1916. Aunque oficialmente se dio a conocer en noviembre de 1917. A los fines de este articulo, lo destacable del acuerdo fueron la definición de fronteras (de Siria e Irak) así como la ocupación militar de Francia en Siria, hasta entrada de década de 1940.

20 Palabra en hebreo, significa mandamiento.
} 
Si bien es cierto que todos los niños judios varones en Alepo recibían educación religiosa, no había uno que no supiera Torá21, no importaba su situación económica, pocos eran los que continuaban estudiando en el nivel, que se conoce como Yeshiva ${ }^{22}$. Mencionamos esto pues, a la edad de 16 (diez y seis) años, Ismael ya era docente en la Yeshiva, donde estudiaba. Dos años después, en 1930, ya era director de Talmud Torá, director del área de estudio, de la enseñanza del pentateuco.

Como podemos observar, desde muy temprana edad dedica su vida a la formación e instrucción de especialista religioso.

Hasta la segunda guerra mundial (1938 a 1945), no hubo grandes inconvenientes en lo que a vida, convivencia, para los y las judios/as residentes en Siria. Sin embargo luego de la declaración de independencia del estado de Israel (1948), el antisemitismo se volvió moneda corriente. A tal punto que Ismael tuvo que tomar la decisión de dónde ir, recibió ofertas de varios países, entre ellos Estados Unidos, pero solo le llamo la atención la de Argentina, fundamentalmente porque el país accedia a acogerle con toda su familia.

La llegada de Ismael a la Argentina, se dio en el año 1953 y duro casi dos meses. Cuando llego, lo hizo asumiendo el rol de guía de una comunidad sefaradí de origen alepino. Poco a poco la congregación fue conformándose con inmigrantes arribados de Alepo que corrian la misma suerte que Ismael, huir de un continente, y un país plagado de antisemitismo, como dijéramos con posterioridad a 1948, cuando se declara la independencia del estado de Israel.

Si bien la comunidad conto con otros especialistas religiosos antecesores, en la comunidad se vivia (hasta la llegada de Ismael), como relatan algunos miembros de la comunidad un alejamiento de las pautas de la vida judia sefaradi, una liberalización de ideas, influencias de las nuevas

21 En hebreo, remite al estudio/enseñanza de lo que se denomina Pentateuco, por ser cinco libros; génesis, éxodo, levítico, números y Deuteronomio.

22 remite al lugar donde se estudia Torá (contiene los cinco libros del pentateuco, génesis, éxodo, levítico, números y Deuteronomio) y Talmud (recoge las discusiones y análisis de rabinos en relación a leyes, tradiciones, costumbres, narraciones y dichos, parábolas, leyendas e historias), en general es sólo para jóvenes (varones). 
generaciones tal vez, con gran impacto de asimilación, dando concesiones y por sobre toda las cosas relajamiento en la observancia ${ }^{23}$.

De entre las razones por las cuales Ismael y no otro, es solicitado como Gran Rabino, es que encarnaba como nadie el modelo que mejor se ajustaba, como aquello que se precisaba en la comunidad en ese momento. A partir de no hacer concesiones en lo que eran para él enseñanzas fundamentales, y esto era; organización, preservar la propia identidad, alguien que velara por el mantenimiento del Kashrut ${ }^{24}$ y de la continuidad de las tradiciones judias ortodoxas sefaradies en general. Puesto que si bien había un interés por el cumplimiento de las mitzvot ${ }^{25}$, había según miembros de la comunidad, e Ismael mismo, una observancia superficial en la Argentina a la que él arribó en 1953.

La primera tarea que tuvo como rabino fue el retorno al estricto cumplimiento del Shabat, Kashrut y Taharat Ha mishpajá ${ }^{26}$. Los límites de la comunidad debian de ser fuertemente marcados, frente al proceso de apertura con que se había encontrado al llegar a la Argentina.

La segunda tarea tuvo que ver con enfrentarse a la comisión directiva, que pensaban en él como un simple empleado. Parte de su legado para los rabinos posteriores a él (en su comunidad como en otras), fue jerarquizar, y profesionalizar el cargo de rabino, que existiera un contrato laboral, con aportes, haberes, y remuneración acorde a las tareas, como las responsabilidades que amerita cumplir tal rol.

En relación con ello, y viendo que tenía diferencias con las generaciones adultas, en términos de cómo ejercer su cargo, como llevar a cabo su tarea, es que decidió focalizar y armar su semillero entre los más

\footnotetext{
23 La cursiva me pertenece.

24 En hebreo, remite a las reglas alimentarias prescriptas por la Torá (antiguo testamento).

25 En hebreo, normas judias.

26En hebreo, pureza de familia, o leyes de familia, remite a todos los cuidados que deben de tenerse para mantenerse puro. Fundamentalmente remiten a la mujer, a sus cuidados en los dias de menstruación, el mikveh (en hebreo), baño que limpia de toda impureza, pudiendo retornar al lado de su esposo, de cómo relacionarse con él estando impura, como vestirse, entre otros.
} 
jóvenes, así armó el Minián ${ }^{27}$ modelo. Comenzó realizando actividades, dentro y fuera de la sinagoga. Incentivándolos a participar y ocupar posiciones de responsabilidad en la comunidad.

Según comentan miembros de la comunidad, siendo Ismael director de Talmud Torá, si se enteraba que sus alumnos se encontraban reunidos con muchachas, averiguaba quienes eran esas jóvenes, llamaba a sus padres, para que las fuesen a buscar. Comentamos esto, pues dentro del judaísmo ortodoxo (tanto sefaradí como ashkenazi), aun hoy día, no suelen reunirse hombres y mujeres bajo un mismo techo, si no se encuentran entre los congregados, padres, hermanos o marido de esa mujer. Todo otro tipo de uniones, debe de hacerse, sobre todo para las mujeres, con su padre, hermano, o en el debido caso, su esposo. Nunca puede quedar sola con otro hombre que no sean los anteriormente mencionados. Esto rige tanto para el judaísmo ortodoxo sefaradí, como para el ashkenazi. Cabe aclarar que cuando hablamos de jóvenes, nos referimos a muchachos que ya hayan celebrado su Bar-Mitzvah. 28

Otro hecho interesante que comentan quienes lo conocieron, es que en la época de vacaciones, entre diciembre y marzo, el rabino solía alquilar una casa en Mar del Plata, asistía al Templo Gabriel29, y para mantener los lazos de la comunidad, instó en abrir una carnicería y un restaurante Kasher, así como una Mikveh ${ }^{30}$, en la ciudad veraniega.

En esta época del año, solía pasar al menos dos horas, todas las tardes enseñando Torá a los niños. Tenía la visión de no dejar espacios librados a la suerte. ¿Pero cómo incentivar a jóvenes en vacaciones, a seguir estudiando? Su solución fue desde premiarlos con dinero, pasando por

27 Remite a un quorum de diez hombres (o personas, según la tradición judía a la que se remita) para la realización de determinados ritos judíos. Serán hombres en la comunidad sefaradí. Hoy en día muchas comunidades judias tienen minian contando a las mujeres, de hecho hay rabinas mujeres.

28 En hebreo, hijo (Bar) de la norma (Mitzvah), remite al rito de iniciación, de paso de la niñez a la edad adulta de los hombres judíos, sean o no ortodoxos, sean ashkenazies como sefaradies.

29 Ubicado en la calle 3 de febrero 2451, Mar del Plata, Buenos Aires. Hoy en día continúa dando servicio.

30 Remite a los baños de purificación, generalmente utilizado por las mujeres, siete (7) dias después de su ciclo menstrual, para poder tener contacto sexual con su esposo. Algunos hombres suelen utilizarlo en la festividad del día del perdón. 
excursiones, hasta armar viajes a Israel para aquellos alumnos de mejor promedio, para continuar perfeccionándose en el aprendizaje.

Al mismo tiempo, para quienes estuvieran en vacaciones en Buenos Aires, solía alquilar una quinta durante todo el mes de Enero. La dinámica era tener medio día de estudio, y medio de descanso. Esto era para los jóvenes varones, aquellos que concurrian a la Yeshiva.

En una intención de cerrar la trayectoria de Ismael, nos gustaría hacernos de sus palabras, de un fragmento del discurso que realizo al cumplirse 30 (treinta) años de su labor al frente de la comunidad

la característica fundamental de mi trabajo es la vocación de servicio a través de la educación, inculcando el cumplimiento de las mitzvot, la observancia del Shabat, kashrut y taharat ha mishpaja (fragmento de discurso de Ismael, década de 1980).

Por su parte Isaías es nieto de Ismael, nació en Argentina a fines de la década de 1970, se crió en un hogar, donde no solo su abuelo, sino también su padre, supieron ser rabinos. En la entrevista que nos brindo, nos compartió parte de sus reflexiones de trayectoria, a continuación daremos cuenta de aquellas que consideramos relevantes para este articulo.

Respecto a su primer contacto con la religión, Isaías reflexiona que fue impuesta, usa esas palabras para dar cuenta de su estilo de vida rebelde y poco definido. Al momento relata que acercándose sus 18 (diez y ocho) años realiza un viaje a Israel, para continuar sus estudios, y es allí donde decide continuar el legado de su abuelo y su padre, a quienes considera como referentes en su vida, en su formación como especialista religioso, así como dentro de su comunidad. También comenta que luego de volver de Israel, nuevamente instalado en la Argentina, recibido como rabino, se casa, y comienza a ir al Koller, que es la Yeshiva para hombres casados.

En este punto, una primera reflexión que podemos hacer, remite a la continuidad en la tradición familiar de ser especialista religioso judío ortodoxo sefaradí dentro de la comunidad alepina en CABA, Argentina. Junto con la continua formación, e instrucción aún en el rol de especialista religioso en cargo. Asimismo podemos mencionar como continuidad el 
mantenimiento del Kashrut, la educación de jóvenes a través de la Yeshiva y los viajes a Israel.

En relación a los viajes, habría que aclarar, que desde la creación del estado de Israel, en 1948, existen multiplicidad de opciones, programas, planes y becas para viajar. En tiempos de Ismael era viajar un año, recibirse de especialista religioso, volver al país de origen y ejercer como rabino, esto sigue vigente hoy día en la Argentina. Isaías menciono en la entrevista el plan de "marcha por la vida"31.

Una diferencia que podemos indicar es que Ismael era el Gran Rabino de la comunidad, en tanto que Isaías es rabino de la escuela en todos los niveles, si bien ambos mantienen contacto con la comunidad toda, consideramos que el acceso y el grado difiere en uno y otro. Mientras que para Ismael en su momento fue directo y constante, fundamentalmente entre los jóvenes, durante todo el año, ciclo lectivo y vacaciones. Isaías mantiene un vínculo dentro del contexto de ciclo lectivo escolar, de lunes a viernes. En el periodo de vacaciones, no mantiene contacto con los jóvenes, ni se planean actividades. Pensando en las anécdotas de quienes supieron conocer a Ismael, que solía llamar a los padres de las niñas que estuvieran en una reunión con varones jóvenes para que las fueran a buscar. Consideramos que hay una ruptura entre estos especialistas religiosos en relación a cómo y cuánto se focaliza en los jóvenes.

Respecto de los especialistas religiosos ortodoxos ashkenazies, podemos indicar que tienen más puntos de contacto con la práctica religiosa en tiempos de Ismael, que en el relato de Isaías. Esto a partir de los cursos que imparten en la sociedad judía toda, para todas las edades.

Todo esto considerando el vínculo cara a cara. Respecto al modo de relacionarse a través de las redes sociales, en los tiempos de Ismael, era más frecuente el vinculo cara a cara, como mucho el teléfono, y las cartas. En la actualidad, Isaías opta por vincularse con los jóvenes cara a cara, dentro de la institución, de lunes a viernes, durante el horario laboral de 7.30am hasta

31 Véase http://www.marchaporlavida.com.ar/ [27/02/2019]. 
las $16.30 \mathrm{pm}$., no tiene redes sociales, como Facebook, Instagram o Tweeter, para dar cuenta de actividades o charlas, o mantener vinculo directo con los jóvenes, a sabiendas de que hoy día las redes sociales es en general el modo en que suelen comunicarse entre sí. Menciona que alguna que otra vez, manda mensajes por Whatsapp pero son contadas. Aquí nuevamente encontramos una diferencia con los especialistas religiosos de Jabad Lubavitch, como dijéramos judíos ortodoxos de ascendencia ashkenazi. Estos tienen vínculo directo, con un gran rango etario, con diversos medios de comunicación como pueden ser Facebook, Tweeter, página web, blog.

Otra diferencia que encontramos en relación a la comunidad, pero fundamentalmente a la comisión directiva, Ismael logro imponerse en su momento, hoy en día Isaías es parte de la comisión.

Un tercer punto a considerar es la modificación en el sistema de rezo, Isaías menciona que fue su aporte. Nos comenta que antes, en tiempos de su abuelo y su padre, el momento del rezo era en el colegio, todos juntos en el mismo horario, menciona la complicación que llevaba en términos de organización, y adiciona su solución, "lo reorganizamos, digamos, por grupos, o sea, cada grado hace su rezo con su moré32. Entonces son números más reducidos y se pudo hacer mejor".

A grandes rasgos, podemos indicar que entre Ismael e Isaias, hay continuidad, puntos de contacto, así como algunas diferencias, en relación a sus trayectorias, en tanto especialistas religiosos. No encontramos rupturas.

En el abordaje de este articulo hemos visto como intervienen cuestiones históricas que hacen a la identidad nacional de la sociedad que es receptora, por ejemplo, el modelo de nación que se fue gestando en las etapas fundacionales y en las subsiguientes, la definición de ciudadano, quién lo es y quién no, el modo en que se fue definido el territorio nacional con las distintas disputas ocupando y defendiendo territorios hasta llegar a su configuración definitiva.

32 Docente, profesor

NORUS | vol. $6, n^{\circ} 10 \mid$ p. 35 I-380 | Ago/Dez/20I8 
Imaginemos ahora la intensidad que debió de ser además para Ismael que venía de Siria, un país que logro su independencia en 1946, que se habla árabe, que tiene costumbres y estilo de vida muy disimiles a la Argentina. Sin embargo el rabino, logro aprender y aprehender, no solo el idioma, sino también los modismos argentinos, adaptados a la comunidad judía ortodoxa sefaradí, proveniente de Alepo, para así poder estar al frente, y ser referente de la comunidad, donde debía de cumplir nada menos que el rol de Gran Rabino. Respecto de Isaías, él mismo indica que si bien provenía de un linaje de especialistas religiosos, fue él quien optó por continuar ese camino, el que considera una ocupación y define su rol como "doctor del alma".

Consideramos pertinente abordar la trayectoria de dos especialistas religiosos, con la especificidad de ser judíos ortodoxos sefaradies, abuelo y nieto, de modo de poder entender desde sus propios discursos, desde su narrativa, qué significa ser rabino, a modo de seguir pensando cómo a partir del lenguaje, que es una forma de construir, narrar y presentar el mundo, se dice lo que "se dice" y cuáles son "las formas de decir", permitiéndonos entonces, conformar relaciones entre diversos grupos dentro de las sociedades no sólo desde las representaciones, sino también desde y, en la convivencia cotidiana. A continuación indicaremos unas reflexiones.

\section{Palabras finales}

En este artículo hemos tenido la intención de dar cuenta la trayectoria de dos especialistas religiosos judíos ortodoxos sefaradíes, de ascendencia siria, intentando echar luz sobre su profesión y estilo de vida, en tanto rabinos. Para lo cual consideramos pertinente en primer lugar, contextualizar en términos de marco socio-histórico, cómo fueron llegando los judios a la Argentina. En segundo lugar se indicaron las diferentes corrientes que existen al interior del judaísmo en este país. Para poder si, profundizar sobre las trayectorias de estos especialistas religiosos, lo cual fue logrado a partir de una historia de vida y una entrevista, pudiendo dar 
cuenta cómo es que toman contacto con la religión, considerando el contexto y particularidades de ambos, su formación, los aportes que han hecho a la comunidad a la que pertenecen, así como su legado.

Considerábamos necesario dar cuenta del camino recorrido por ambos en tanto educadores, maestros y líderes de su comunidad, sumergidos en la tradición judía ortodoxa sefaradí. Donde supieron hacer un buen uso de sus herramientas, unirlas, aplicar desde sus experiencias de vida, y desde sus formaciones, todos los saberes que pudieran ayudarles a transmitir el mensaje a nuevas generaciones. Fundamentalmente la formación, y el cumplimiento de las tradiciones, girando en torno a la obligación de un estudio constante, y ascendente.

Como hemos buscado mostrar en esta oportunidad, el hecho de hablar de trayectoria tomando dos generaciones invita a la reflexión respecto de la movilidad (espacial y social), así como la estratificación social. Consideramos que remite además a la integración social, en términos de proceso, considerando aprendizajes, transformaciones, continuidades y rupturas.

\section{Referências}

ABDELUAHED, akmir (coord.). Los árabes en América Latina: Historia de una Emigración. Madrid: Editorial Siglo XXI, 2009.

ABDELUAHED, akmir. Los árabes en la Argentina. Rosario, Argentina: UNR Editora, 2011.

ARANGO, J. La explicación teórica de las migraciones: luz y sombra. México: Revista Migración y Desarrollo, No 1, 2003.

AAVV. Sirios, Libaneses y Argentinos: Fragmentos para una historia de la diversidad cultural argentina. Argentina: Fundación Los Cedros. Editorial Cálamo, 2004.

ARFUCH, Leonor. El espacio biográfico en las Ciencias Sociales: en El espacio biográfico. Buenos Aires: Fondo de Cultura Económica, 2008a. 
ARFUCH, LEONOR. Travesias de la identidad. Una lectura de relatos de vida: en El espacio biográfico. Buenos Aires: Fondo de Cultura Económica, 2008b.

BALAN, J. y JELIN, E. La estructura social en la biografia personal. Buenos Aires: Estudios CEDES, 1979.

BALÁN, J. Las migraciones internacionales en el Cono Sur. Buenos Aires: Cedes, 1985.

BARGMAN, D. Rabbi Itzjak Chehebar: Un visionario. Buenos Aires: Congregación sefaradi, 1995.

BECK, Ulrich. Individualización, institucionalización y estandarización de las condiciones de vida y de los modelos biográficos: en La sociedad de riesgo. Hacia una nueva modernidad. Barcelona: Paidós, 2010.

BENCHIMOL, I. Contra viento y marea: Una aproximación a la obra del Ribbi Zeev Grimberg, Z'L. Buenos Aires: edición del autor, 2007.

BERTAUX, Daniel. E1 enfoque biográfico, su validez y sus potencialidades. París: Revista Cahiers Internationaux de Sociologie, Vol. LXIX, (traducción TCU 0113020 de la Universidad de Costa Rica), 1980.

BERTAUX-WIAME. Life Stories in the Bakers Trade: Biography and Society. The Life History Approach in the Social Scencies. California: Sage Publications, 1981.

BIANCHI Susana. Historia de las religiones en la Argentina. Las minorias religiosas. Buenos Aires: Editorial Sudamericana, 2004.

BLANCO, Mercedes. Trabajo y familia. Entrelazamiento de trayectorias vitales. Argentina: Revista Estudios Demográficos y Urbanos, núm. 51, septiembre-diciembre, 2002.

BLANCO, Mercedes. El enfoque del curso de vida: origenes y desarrollo. Argentina: Revista Latinoamericana de Población, vol. 5, núm. 8, enerojunio, 2011.

BOURDIEU, P. Prefacio: en Sayad, A. La doble ausencia. De las ilusiones del emigrado a los padecimientos del inmigrado. Barcelona: Anthropos, 2010 . 
BOURDIEU, P. El espacio de los puntos de vista: miseria del mundo. Buenos Aires: Fondo de Cultura Económica, 2007.

BOURDIEU, P. Las formas del capital. Capital económico, capital cultural y capital social: Poder, derecho y clases sociales. Bilbao: Desclée de Brouwer. 2da edición, 2001.

BOURDIEU, P. La ilusión biográfica: Razones prácticas. Sobre la teoría de la acción. Barcelona: Anagrama, 1997.

BOURDIEU, P. Las reglas del arte. Génesis y estructuras del campo literario. Barcelona: Anagrama, 1995.

BOURDIEU y WACQUANT. Respuestas por una antropologia reflexiva. México, D. F.: Grijalbo, 1986.

BOURDIEU, P. Sociologia y cultura. México: Grijalbo, 1984.

BOURDIEU, P. Campo intelectual y proyecto creador: AA.VV., Problemas del estructuralismo. México: Siglo XXI, 1969.

CASTLES, S. and MILLER, M.J. The age of migration: international population movements in the modern world. London: Macmillan, 1993. CABABIE'- SCHINDLER, Valeria. Imah on the Bimah: Gender and the Roles of Latin American Conservative Congregational Rabinas. Florida International Universisty: Electronic Theses and Dissertations. Paper 353, 2011.

CERRUTTI, Marcela. Diagnostico de las poblaciones de inmigrantes en la Argentina: Serie de documentos de la Dirección Nacional de Población No2. Buenos Aires: Dirección Nacional de Población, Ministerio del Interior-OIM, 2009.

CHASE, Susan. Narrative Inquiry: Multiple Lenses, Approaches, Voices: DENZIN, Norman y LINCOLN, Yvonna (Eds.): The Sage Handbook of Qualitative Research, Thousand Oaks. California: Sage Publications, 2005. CONDE, Idalina. Falar da Vida (I). Portugal: Revista Sociologia. Problemas e Práticas, n $15,1994$.

CONDE, Idalina. Falar da Vida (II) Portugal: Revista Sociologia. Problemas e Práticas, nº 16, 1995. 
CÓRDOVA, Víctor. Historias de Vida. Caracas: Fondo Editorial Tropykos, 1990.

DALLE, Pablo. Movilidad social ascendente de familias migrantes de origen de clase popular en el Gran Buenos Aires. Santiago del Estero: Revista Trabajo y Sociedad $\mathrm{n}^{\circ}$ 21, Universidad Nacional de Santiago del Estero, 2013.

DELORY-MOMBERGER, Christine. Biografización y socialización: Biografía y educación. Figuras del individuo-proyecto. Buenos Aires: FLACSO - Facultad de Filosofia y Letras, UBA, 2009.

DE MIGUEL, JESÚS M. Auto/biografias. Madrid: Centro de Investigaciones Sociológicas, 1996.

DEVOTO, F., Historia de la inmigración en la Argentina. Buenos Aires. Ed. Sudamericana, 1995.

DUVIGNAUD, Jean. La Historia y lo cotidiano. Barcelona: Peninsula, 1991.

DUVIGNAUD, Jean. Sociologia del Conocimiento. México: Fondo de Cultura Económica, 1979

EGAN, E.W. Argentina in pictures. Minneapolis: Lerner Publications Co, 1988.

ELDER, Glen. History and the Life Course: BERTAUX, Daniel, Biography and Society. The Life History Approach in the Social Scencies. California: Sage Publications, 1981.

FAINSTEIN, Daniel. Secularización, profecia y liberación: la desprivatización de la religión en el pensamiento judio contemporáneo. Un estudio comparativo de sociologia histórica e historia intelectual: Tesis doctoral. México: Universidad Nacional Autónoma de México, 2006.

FERRAROTTI F. La historia y lo cotidiano. Madrid: Ediciones Península, Homo Sociológicus 48, 1991.

FERRAROTTI F. Historia oral e historias de vida. San José, Costa Rica: Biografia y Ciencias Sociales en Flacso, Cuadernos de Ciencias sociales, nro. 10, 1988 [1983].

FERRAROTTI F. Storia e storie di vita. Roma-Bari: Laterza, 1981. 
FLICK, Uwe. Las narraciones como datos: Introducción a la investigación cualitativa. Madrid: Morata, 2004.

FORNI, MALLIMACI, CÁRDENAS. Guia de la diversidad religiosa de Buenos Aires: Tomo 2. Buenos Aires: Editorial Biblós, 2008.

FORNI, MALLIMACI, CÁRDENAS. Guía de la diversidad religiosa de Buenos Aires: Tomo 1. Buenos Aires: Editorial Biblós, 2003.

GEERTZ. La interpretación de las culturas. Barcelona: Gedisa, 2005 [1973].

GERMANI, Gino. Clase social subjetiva e indicadores objetivos de estratificación. Buenos Aires: Universidad de Buenos Aires. Facultad de Filosofia y Letras. Instituto de Sociología, 1963.

GIDDENS, Anthony. La trayectoria del yo: Modernidad e identidad del yo. El yo y la sociedad en la época contemporánea. Barcelona: Península, 1998. GRANERO, M. G. Migración como frontera identitaria: ponencia presentada en el III Congreso Internacional -X Simposio- de América Latina y el Caribe. Buenos Aires: FCE-UBA, 2012.

HAKISS, Agnes. Ontologies of the self: on the mythological rearranging of one's life history: BERTAUX, Daniel: Biography and Society. The Life History Approach in the Social Sciences. Beverly Hills, California: Sage Publications, 1981.

HERSZKOWICH Enrique. Historia de la Comunidad Judia Argentina. Su aporte y participación en el pais. Argentina: DAIA publicaciones. Disponible

http://www.daia.org.ar/2013/uploads/documentos/69/cuad\%20historia\% 20com\%20judia.pdf [27/02/2019].

JOZAMI, Gladys. La identidad nacional de los llamados turcos en la Argentina. Argentina: Temas de África y Asia 2, 1993.

$\mathrm{KLICH}$, Ignacio. árabes $\mathbf{y}$ judíos en América Latina. Historia, representaciones y desafios. Buenos Aires. Argentina: Editorial Siglo XXI, 2006. 
KORNBLIT, Ana Lía. Historias y relatos de vida: una herramienta clave en metodologias cualitativas: Metodologías cualitativas en ciencias sociales. Modelos y procedimientos analiticos. Buenos Aires: Biblos, 2007.

KVALE, Steinar. Planificación de la entrevista: Las entrevistas en investigación cualitativa. Madrid: Morata, 2014 ${ }^{\mathrm{a}}$.

KVALE, Steinar. Variaciones de la entrevista: Las entrevistas en investigación cualitativa. Madrid: Morata, 2014b.

LECLERC-OLIVE, Michele. Temporalidades de la experiencia: las biografias y sus acontecimientos. México: Revista Iberofórum. Revista de Ciencias Sociales, Universidad Iberoamericana, 2009.

MAGRASSI, G. E. y ROCA, M. M. La Historia de Vida. Buenos Aires: Centro Editor de América Latina, 1980.

MALLIMACI, F. y DI STÉFANO N. (comp.). Religión e imaginario social. Buenos Aires: Manantial, 2001.

MALLIMACI F., GIMÉNEZ BÉLIVEAU V. Historias de vida y método biográfico: Estrategias de Investigación cualitativa. Barcelona: Gedisa, 2006.

MALLIMACI F., GIMÉNEZ BÉLIVEAU V. Creencia e increencia en el Cono Sur de América: Entre la religiosidad difusa, la pluralización del campo religioso y las relaciones con lo público y lo politico. Argentina: Revista Argentina de Sociología, No9, p.44-63, 2007.

MALLIMACI F., ESQUIVEL, J. y GIMÉNEZ BÉLIVEAU V. Creencias religiosas y estructura social en Argentina en el siglo XXI. Argentina: Boletín de la Biblioteca del Congreso de la Nación Creencias, politica y sociedad, 124, 75$100,2009$.

MALLIMACI F (coord.) Atlas de las creencias religiosas en Argentina. Buenos Aires: Biblos, 2008.

MARTÍNEZ, Ana Teresa. Introducción. Religión y Creencias en el trabajo sociológico de Pierre Bourdieu: La Eficacia simbólica. Religión y política. México: Editorial Biblos, 2009. 
MARTÍNEZ PIZARRO, J. Medición e información sobre la migración internacional a partir de los censos: lecciones, desafios y oportunidades Santiago de Chile: Notas de Población No. 88. CEPAL, 2009.

MECCIA, Ernesto. Subjetividades en el puente. El método biográfico y el análisis micro-sociológico del tránsito de la homosexualidad a la gaycidad. Argentina: Revista Latinoamericana de Metodología de la Investigación Social, Nº4, año 2, 2013.

MINCER, Jacob. Family Migration Decisions en Center for economic analysis of human behavior and social institutions. New York, N.Y: National Bureau of Economic Research, Inc., 1978.

MONTENEGRO, Silvia. Imigrantes árabes na fronteira sul-americana: narrativas de trabalho, religião e futuros imaginados. São Paulo: Rever. Revista de Estudos da Religiao, Pós-Graduacão em Ciencias da Religião, 2012.

PLUMMER, Ken. Los documentos personales. Madrid: Siglo XXI editores, 1989.

POIRIER, Jean. Les récits de vie. París, France : Presses Universitaires de France, 1983.

PPRINS, Gwyn. Historia oral: BURKE, Peter (Editor): Formas de hacer historia. Madrid: Alianza, 1996.

PUJADAS MUÑOZ, Juan José. E1 método biográfico: E1 uso de las historias de vida en ciencias sociales. Madrid: Centro de Investigaciones sociológicas, 1992.

RAANAN, Rein (coord.). Árabes y judios en Iberoamérica. Similitudes, diferencias y tensiones. España: Colección Ánfora, 2008.

ROSENBERG, Shalom y RUBINSTEIN-NOVICK, Daniel. El rol de la tradición religiosa en la comunidad judia en la Argentina. Israel: Universidad Hebrea de Jerusalén, Instituto de Judaísmo Contemporáneo, Contribución de la Asociación Mutual Israelita Argentina, 1961.

SANTAMARINA, Cristina y MARINAS, José Miguel. Historias de vida e historia oral: DELGADO, Juan Manuel y GUTIÉRREZ, Juan: Métodos y 
técnicas cualitativas de investigación en ciencias sociales. Madrid: Fundamentos, 1995.

SAYAD, Abdelmalek. La doble ausencia. De las ilusiones del emigrado a los padecimientos del inmigrado. Barcelona: Anthropos, 2010.

SCHNAPPER, Dominique. Qu'est-ce que 1'integration? París : Gallimard, 2007.

SOLIMANO, Andrés. Development cycles, political regimes and international migration: Argentina in the twentieth century. Economic Development Division. Santiago de Chile: N.22, ECLAC/CEPAL, 2003. VALLES, Miguel S. E1 trabajo de campo en las entrevistas cualitativas: Entrevistas cualitativas. Madrid: Centro de Investigaciones Sociológicas, $2002^{\mathrm{a}}$.

VALLES, Miguel S. Análisis y sintesis de entrevistas cualitativas: Entrevistas cualitativas. Madrid: Centro de Investigaciones Sociológicas, 2002 b.

VASILACHIS DE GIALDINO, I. Estrategias de investigación cualitativa. Barcelona España: Editorial Gedisa S.A., 2006.

VASILACHIS DE GIALDINO, I. Métodos Cualitativos II La práctica de la investigación. Buenos Aires: Centro Editor de América Latina S.A., 1992.

VASILACHIS DE GIALDINO, I. Métodos Cualitativos I. Los problemas teóricos-metodológicos. Buenos Aires: Centro Editor de América Latina S.A., 1993.

VEGANZONES, Marie-Angev. Argentina in the twentieth century. Paris: OECD, 1997.

WEBER, Max. Economia y sociedad. México: Fondo de Cultura Económica, 1984.

WIEVIORKA, Michel. La diferencia cultural como cuestión social: Razas en conflicto. Barcelona: Anthropos Editorial, 2002. 